See Article page 177.

\section{Commentary: Not many tools in the toolbox}

\author{
William T. Mahle, MD
}

The outcomes for children who need support with a ventricular assist device (VAD) have improved dramatically over the past 3 decades owing to several factors. The use of a VAD for a young child with dilated cardiomyopathy can now be achieved with a high rate of success and relatively low morbidity. However, the pediatric cardiothoracic surgeons care occasionally confronted with more challenging cases. Moon and colleagues ${ }^{1}$ describe the use of a continuous flow device in a young child with restrictive cardiac physiology. This report highlights the challenges of using adult devices in small children, particularly when the anatomy and physiology are atypical. The use of adult devices in small children is challenged by the small ventricular cavity size. This is exacerbated further in the setting of restrictive physiology. In this case, the authors chose to utilize a HeartWare HVAD (Medtronic, Minneapolis, Minn). The decision to use this device was driven in part by the desire to discharge to home. Notably the only approved device for a child this size (ie, Excor; Berlin Heart, Berlin, Germany) does not permit discharge to home. In order to accomodate the HVAD device in such a case several surgical modifications could be considered. Some surgeons have performed thinning of the ventricle in the body of the left ventricle to create more room. ${ }^{2}$ Alternatively, atrial cannulation can be considered. However, atrial cannulation in a child with height $<100 \mathrm{~cm}$ certainly would create its own challenges.

From the Division of Cardiology, Department of Pediatrics, Emory University School of Medicine, Atlanta, Ga.

Disclosures: The author reported no conflicts of interest.

The Journal policy requires editors and reviewers to disclose conflicts of interest and to decline handling or reviewing manuscripts for which they may have a conflict of interest. The editors and reviewers of this article have no conflicts of interest.

Received for publication May 28, 2021; revisions received May 28, 2021; accepted for publication June 1, 2021; available ahead of print June 4, 2021.

Address for reprints: William T. Mahle, MD, Division of Cardiology, Department of Pediatrics, Emory University School of Medicine, 1405 Clifton Road, Atlanta, GA 30322 (E-mail: wmahle@emory.edu).

JTCVS Techniques 2021;8:182

2666-2507

Copyright (C) 2021 The Author(s). Published by Elsevier Inc. on behalf of The American Association for Thoracic Surgery. This is an open access article under the CC BY-NC-ND license (http://creativecommons.org/licenses/by-nc-nd/4.0/).

https://doi.org/10.1016/j.xjtc.2021.06.001

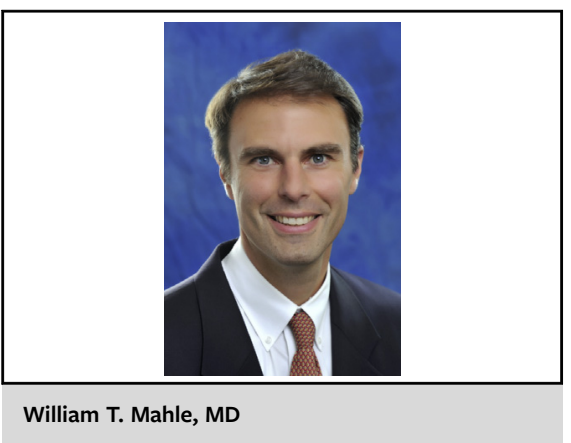

CENTRAL MESSAGE

Use of VADs designed for adults

but placed in small children pose

significant challenges. Clinicians

need to tailor the implant and

the VAD settings to the unique

physiology.

Another key point highlights the use of the waveform data from the HeartWare HVAD, which rely on the HQ curves. The authors' attention to the subtleties of the waveform in this case report is admirable, particularly during the early postoperative period when fluid status and vascular resistance is variable. Frequent alternations to the setting of continuous flow device in young children is often required to work around these complications such as suction events.

The troubleshooting described by Moon and colleagues ${ }^{1}$ underscores that postoperative physiologic manipulation, rather than surgical implant, may be the most challenging element of VAD management in some children. Clinicians need to be mindful that all currently available devices for a patient of this size and physiology have some significant limitations. Whether devices still under investigation such as the Jarvik 2015 (Jarvik Heart, New York, NY), which is studied in the Pumps for Kids, Infants and Neonates (PumpKIN) trial, could offer a smoother course remains to be determined. One hopes that all clinical centers use the data presented here and consider all possible devices and implant strategies to best bridge complex pediatric patients with advanced heart failure to transplantation.

\section{References}

1. Moon J, Tunuguntla H, Adachi I. Waveform-guided management of implantable ventricular assist device in a small child. J Thorac Cardiovasc Surg Tech. 2021; 8:177-81.

2. Sreenivasan J, Kaul R, Khan MS, Ranka S, Demmer RT, Yuzefpolskaya M, et al. Left ventricular assist device implantation in hypertrophic and restrictive cardiomyopathy: a systematic review. ASAIO J. 2021;67:239-44. 